\title{
Misconception in Chemistry Education and Practices to Eliminate Them: Literature Analysis
}

\author{
Musa Üce ${ }^{1}$, İlknur Ceyhan ${ }^{1}$ \\ ${ }^{1}$ Marmara University, Faculty of Education, Department of Educational Science and Mathematics, Istanbul Turkey \\ Correspondence: Marmara University, Faculty of Education, Department of Educational Science and Mathematics, \\ Istanbul Turkey.
}

Received: January 26, 2019

Accepted: February 24, $2019 \quad$ Online Published: February 26, 2019

doi:10.11114/jets.v7i3.3990

URL: https://doi.org/10.11114/jets.v7i3.3990

\begin{abstract}
Concepts can be examined in two groups as abstract and concrete ones. While concrete concepts are improved as a result of students' experiences, it is considerably challenging for students to perceive abstract concepts. Since chemistry includes abstract concepts largely, it is considered to be hard to comprehend as a class by students. In fact, studies confirm this thought. On this particular issue, based on literature, it is clearly stated that students present themselves in learning environment, having some sort of thoughts and acknowledgments which are scientifically incorrect by a majority. The false information or acknowledgments are called misconception in the literature. Furthermore, it is also indicated that it is too hard to eliminate such misconceptions via the traditional teaching methods. Since each student constructs his/her own knowledge, understanding and concepts in accordance with his/her ability and experience, what matters here is, if prior knowledge of student involves any misconceptions, to identify and eliminate misconceptions. In this context, researches on identification and then elimination of misconceptions make a significant contribution to the chemistry education. In this paper, misconceptions determined and identified in literatures on subjects considered to be abstract, complex and hard to understand for students in the field of chemistry education are studied, namely solubility equilibrium, covalent bonds, ionic bonds, hydrogen bond and molecule geometry, activity concept in elements, chemical equilibrium, dissolution, electrolyse and battery; methods to remove those misconceptions are discussed; and in this study, the method of literature review, one of the qualitative research patterns, is used. To conclude, multiple misconceptions in chemistry education, specially related to abstract subjects were determined, and it is confirmed based on the literature that the methods developed in the framework of constructivist learning theory are used to remove such misconceptions.
\end{abstract}

Keywords: misconceptions, chemistry education, constructivist learning

\section{Introduction}

The main objective of learning and teaching methods is to realize a meaningful learning. In order to achieve that, it is required for a student to filter his/her acknowledgments obtained from the external world within his/her own cognition. In this context, fundamental concepts must be recognized thoroughly. Generally, it is possible to identify incorrect prior knowledge preventing meaningful learning as misconceptions. Because understanding a chemical concept requires identification at both macroscopic and microscopic level, students may develop several misconceptions considering abstract concepts (Ürek \& Tarhan, 2005; Canpolat, Pınarbaş1, Bayrakçeken \& Geban, 2004; Novick \& Nussbaum, 1981).

According to literatures, various in-class practices may cause misconceptions for students. Skelly \& Hall (1993) stated that wording, style, metaphors and symbols could induce misconceptions for students. As stated, wording and style can lead to misconceptions and it is challenging to learn the language or wording of chemistry. Thus, when meanings of words are examined, it is seen that they have different meanings than how they are articulated in daily life. Especially in a chemistry class, terms and words used by teachers related to a particular subject may be interpreted variously by students (Veiga, Pereirave \& Maskill,1989; Şen \& Yılmaz,2013). Besides, information on the Net may cause misconceptions, too (Sesen \& İnce, 2010).

Another reason for misconceptions stated in literatures is that teachers may neglect the students' level of preparedness and students may not have the proper and enough prior knowledge to perceive the concepts (Sweller, 1998). Moreover, course books guide teachers and students in respect of establishing content of teaching and planning of teaching process 
in thousands of classes throughout the country, they may also play a major role in developing misconceptions (Kıliç, 2007). All those mentioned above, together with the advancement in science and technology, require a change in the perspective for science education and teaching methods applied in classes. Hence, several new teaching techniques have emerged in education. Along with the changing perspective, traditional teaching methods which do not emphasize researching and questioning, where teacher is placed at the center, have been replaced by constructivist learning methods that students are at the center of the class, learning actively by performing and experiencing, constitute their knowledge by themselves in their minds and teacher functions as a guide or mentor.

According to the constructivist learning method, students try to interpret the new information which they encounter benefitting from their former prior knowledge. This situation stresses the significance of the present prior knowledge in learning process (Canpolat, Pınarbaşı, Bayrakçeken \& Geban,2004). In this context, there is a consensus in literatures among the chemistry educators and researchers that misconceptions should be determined and eliminated. Hence, identifying misconceptions and then improving teaching methods to remove those misconceptions is an important and wide field of research in chemistry education. From this point of view, in this study, misconceptions identified in the current literature related to chemistry education and methods to remove those misconceptions are discussed.

\section{Method}

The essential purpose of researches undertaken in the field of education is to discover the perceptions and subjective viewpoints of students. In this regard, data obtained from researches should provide a profound understanding and acknowledgment of people and subjects. In this case, instead of quantitative research methods where data are indicated numerically, qualitative research methods which fundamentally pursue the processes of observation, meeting, interview and literature analysis are used.

The most important source of information on subjects and people are written literature, so it is very crucial to examine and study written literatures in the field education and even in every field. Thus, according to the literature, since the duty of a researcher is to provide the communication of knowledge, it may be claimed that analyzing the written literature is required (Day, 1998). Especially, analyzing the written literatures in the field of education and revealing their outcomes provides great convenience to researchers in terms of conveying information. When these thoughts above are taken as a basis, this study is constituted via the method of literature analysis, one of the methods of qualitative research.

According to Şimşek \& Yıldırım (2008), analyzing literature is doing a research on written materials including information about the subjects to be studied. Analyzing literature in qualitative researches is a method used when direct observation or interview is not possible or with the intent of enhancing validity of study. In this sense, as well as it may be used solely as a method of research, it may be used along with other methods. By this means, researcher can obtain the requested information without using the methods of observation and interview or can use literature in a way to support the methods of observation and interview, and validity of study is managed to be increased (Glesne, 2012). In this context, the literatures with an accepted validity related to the subject are examined in this study and appropriateness of the literatures examined is confirmed by an expert opinion. Misconceptions determined in each literature and the methods of eliminating them are examined in detail, put into report form and so it is tried to provide the validity of this research.

Samples of this study consist of the literatures related to the misconceptions in chemistry education, accessible in various databases between 2000 and 2016, and also the methods to eliminate those misconceptions. The purpose of this study requires a thorough literature analysis, as the first step of the research, the literatures among the samples, containing the misconceptions determined in chemistry education and methods to eliminate those misconceptions, have been read independently. Misconceptions and methods for elimination involved in the literatures have been examined. After sample literatures were read, misconceptions and the methods to remove them have been meticulously examined one more time, and out of those examined, the literatures to be involved in this study have been chosen and stated in a chart. After all the literatures examined in this study were categorized based on the criteria of literature analysis by the prime researcher, a subsidiary coder has carried out the coding of the literatures. It has been tried to make correspond between the criteria determined and coding practices. The high rate of consistency (\%95) between two coding practices have been accepted as an indicator for the credibility of the analysis in particular and of the research in general (Miles \& Huberman, 1994).

When the literature is examined, it is stated that there is a consensus on the fact that misconceptions may be observed in any age group, and for a sufficient chemistry education, misconceptions must be determined and eliminated. Based on this information in the literature, this study, aiming to examine the misconceptions identified in chemistry education and practices to eliminate them, will provide benefit since it constitutes a source for researches. 


\section{Findings}

The fundamental objective of literature titled "The Impact of Conceptual Change Approach on Students in terms of their Comprehension of Solubility Equilibrium", written by Önder \& Geban (2006), is that it makes a comparison between the teaching method grounding on the conceptual change approach, and the teaching style using traditional methods, within the context of their impacts on $10^{\text {th }}$ grade students' comprehending the issue of solubility equilibrium. In this sense, students are separated into two groups as experimental and control group, and experimental research plan in literature is applied. It is stated that students in the experimental group are trained and taught through the conceptual change approach where conceptual change texts are used while students in control group are taught chemistry designed based on traditional methods. And some of the misconceptions identified in the literature are as follows: "Dissolution and sedimentation stops or end in equilibrium state", "while solubility product is written, solids play a part, too", "Dissolution rate increases overtime; adding a saturated solution a bit more of its solid increases ion concentration", "Dissolution of another solid salt (not constituting a compound with ions in solution) in a saturated solution does not change solubility". When literature is examined generally, it is confirmed that students have many misconceptions preventing them to learn the concept of solubility equilibrium and the teaching method based on the conceptual change approach is more efficient compared to the traditional methods.

The purpose of the literature titled "Removing the misconceptions of high school second grade-students on the chemical equilibrium subject by the means of the method of Analogy" is to help the students of mentioned grade perceive the chemical equilibrium subject via analogy, to determine misconceptions and eliminate them through analogy. In the literature above, a test with multiple choices and true-false questions is applied to the second-grade high school students before and after teaching by researchers in order to determine the misconceptions in that particular subject. Five analogies are applied in groups on the students in the experimental group during the teaching process while traditional teaching methods are used for the control group. In this study, some of the misconceptions detected are as follows: "The decrease ratio in the concentration of reactants equals to the increase ratio in the concentration of products", "While reaction is about to be at equilibrium, the velocities of forward and reverse reaction increase evenly." "When reaction is at equilibrium, concentrations of reactants are equal to the concentrations of products.", "When reaction is at equilibrium, the concentrations of reactants and ...products. change in time", "When reaction is at equilibrium, the concentrations of reactants and. Products constantly change as they go between reaction products and reactants", "When reaction is at equilibrium, velocity of forward and reverse reaction are equal to each other and change", "When reaction is at equilibrium, velocities of forward and reverse reaction are not equal to each other", "When reaction is at equilibrium, in the case when equilibrium is disturbed by the temperature increased, the velocity of reaction is higher than the velocity of reverse reaction", "When reaction is at equilibrium, in the case when equilibrium is disturbed by the volume decreased, the velocity of reverse reaction immediately decreases; when reaction is at equilibrium again as a result of increasing temperature, the velocities of forward and reverse reaction are equal to the value at the first equilibrium", "When reaction is at equilibrium, in the case when catalyser is added into reactor, the fact that velocities of forward and reverse reactions do not change or increase is related to reaction affinity of catalyser with forward or reverse reaction.". In this context, it is confirmed that students have several misconceptions preventing them to learn the chemical equilibrium subject. When the literature is analyzed, it is stated that misconceptions of students in experimental group can be eliminated by using analogies.

The objective of the literature titled "Concept Cartoons as A Teaching Method To be used in Science classes in respect of the contributions to the Constructivist Learning Process", authored by Kabapinar (2005) is stated as to define the benefit of teaching based on concept cartoons. In this sense, concept cartoons about various concepts of chemistry class are prepared in the literature and used in primary school-level classes, so contributions of this method to the constructivist process are stated in the study mentioned above. The researcher has pursued his study on $4^{\text {th }}$ and $5^{\text {th }}$ graders. The students' way of thinking is once mentioned individually and one more time in in-class discussion platform. As a result of this situation, it is ascertained that concept cartoons are available to reveal the students' individual way of thinking without being influenced by in-class interaction. The misconceptions identified in the literature are as follows: the misconception that mass of a particular amount of water may change in accordance with its physical state; another one is the misconception about the position of sugar molecules in sugared water mixture: It is stated in the literature that most of the students have the misconception namely "Sugar molecules are rather placed at the bottom of the mixture", while a few of them believe "Sugar molecules are mostly present at the top of sugared water mixture". In the study mentioned above, it is generally discussed that misconceptions can be eliminated through concept cartoons and the method of concept cartoons is recommended by the researcher to remove misconceptions.

In the literature authored by Üce (2015) with the title "Using Model in Teaching Chemical Bond: Ionic bond, Covalent bond, Dual and Triple Bonds, Hydrogen Bond and Molecular Geometry", it is identified that the researcher aims developing new materials and use them in classes in order to prevent students from developing misconceptions or to 
remove the misconceptions already developed. Within this context, first, the misconceptions identified before related to the subject are mentioned, and then the ways to remove those misconceptions are emphasized. Making use of models, students are got to make models from play dough, and in order to have the chemical bonds subject perceived better, a student-centered, weak experimental designed study (pretest-posttest one-group without random assignment) is pursued for 40 freshmen under teacher's supervision in Spring term of 2010-2011 Academic Year. Some of the misconceptions detected in the literature related to the subject in question are like these: in their study on covalent bonds, Peterson, Treagust \& Garnett (1989) identify that students have misconceptions related to pond polarity, molecule form, molecular polarity, intermolecular bonds and octet rule. Raymond and his friends also state that students have misconceptions about bond polarity, molecule forms, molecular polarity, intermolecular forces and octet rule (Raymond, F. Peterson \& Treagust, 1989). Nicoll (2001) has discovered that students confuse ionic, covalent and hydrogen bonds and cannot define covalent bond. Coll \& Taylor (2001) have identified such misconceptions of students: intermolecular covalent bond is a weak bond, polar covalent compounds are charged, compounds including hydrogen like $\mathrm{HCl}$ are in an ionic form. In a study on bond polarity, molecular polarity, theory of VSEPR, Lewis structure and molecule forms, it has been confirmed that university students cannot distinguish the relation between molecular polarity and bond polarity, cannot determine polar and apolar molecules, and think that electron pair which is not involved in the bond on centre atom does not have any influence on geometrical shape of molecule (Yilmaz \& Morgil, 2001). Some of the misconceptions identified by Ünal, Özmen, Demircioğlu \& Ayas (2002) in their study upon chemical bonds are as follows: "Hydrogens of ammoniac are at equal distance to each other and their bond angles are $120^{\circ}$ ", "Molecular form of water is linear, molecule of carbon dioxide is polar", "Hydrogen bond cannot be developed between hydrogen atom and sulphur atom, intra molecular bond in hydrogen chloride is either ionic bond or hydrogen bond", "Since molecules diverge via the rising temperature, bond angle and bond length increase". And when it comes to the misconceptions about chemical bonds detected by Özmen (2007) among university students, they are: "There is equal electron sharing in all covalent bonds", "electron pairs not involved in bond formation and present in each atom define the polarity of the bond", "molecule forms are only defined by impulses between the electron pairs forming bonds, without paying attention to electron pairs not involved in the bond", "electrons not involved in bond formation in molecules turn molecule into polar". As a conclusion of literature analysis, it is confirmed that making students create models and use them while expressing chemical bonds is beneficial for removing misconceptions.

The objective of the literature titled "An implementation of a Guiding Material based on Constructivist-Active Learning to Eliminate Misconceptions on Ionic Bonds" by Kayalı \& Tarhan (2004) is to determine the misconceptions on ionic bonds, which is included in the unit named chemical bonds where there are misconceptions to a high degree, and then to be able to remove those misconceptions via active learning practices based on constructivist model. After the chemical bonds unit was covered and completed, a pretest including 12 questions totally - seven are multiple choice and 5 open-ended - have been applied to a student group of 32, high school first graders, in order to determine the misconceptions on ionic bonds, and then interviews have been made. Some of the misconceptions identified are as follows: "A metal constitutes an ionic bond with a nonmetal through electron exchange in equal number", "Between two oppositely charged ions, an ionic bond is occurred", "Salt of ions with more positive and negative charge is stronger and harder", "Hardness of solid salt stems from the strength of ionic bond", "NaCl's come side by side and solid white salt is formed" "When salt crystal is broken, $\mathrm{NaCl}$ 's diverge.", "NaCl's in salt are lined up in cube-forms". Later, a guiding material on ionic bonds based on the constructivist model has been prepared by researchers. In the guiding material, why-inspection related to the unit has been given priority and importance, and a special attention has been paid to include enough shapes, figures, photographs and graphics on the subject. Cooperative learning activities, experimental practices, computer animations and reading passages are included in teaching. After teaching via the guiding material, posttest has been applied by researchers, and students and teachers have been asked their opinions on the guiding material implementations prepared. Having evaluated the conclusions of the literature statistically, researchers state they have come to the conclusion that the guiding material is helpful for eliminating the identified misconceptions.

Written by Bilgi \& Şahin (2012), the literature titled "The Impact of Using Computer-assisted Teaching Material in Teaching the Concept of Activity in Elements upon Student's Success" aims to examine the efficiency of computer-assisted teaching in teaching the concept of activity comparing with the traditional chemistry teaching method. In parallel with this purpose, successes shown by students in studying and explaining the given incidents related to activity have been examined in the literature above. This research has been done with the participation of 67 students of $11^{\text {th }}$ grade. It is stated by the researchers that some of the materials used are obtained from internet sources and being re-arranged, and some of them are being prepared by the researchers using the program named Macromedia Flash 8,0. Totally 4 activities have been practiced in the literature. After implementation, researchers have prepared the questions raised at the students to measure the success only after the pilot studies were undertaken. It is stated that existence of some misconceptions about activity, which had not been mentioned before, has been identified in this study. The first of 
those misconceptions is that "When charge balance is provided, every reaction will take place". It is confirmed that there are students having this misconception both in control and experimental group. Another misconception is that "There is a relation between ionic charge and tendency to gain electrons". There are students who think that as ionic charge increases, ion's tendency to gain electrons would increase, too. A third misconception observed is that "Any kind of liquid can be kept in noble metal containers". This misconception is identified only in the control group. Due to the activities carried out in the experimental group, this misconception could be eliminated. When the literature is examined in general, it is concluded that computer-assisted teaching has been effective considering the elimination of misconceptions about activity.

In the literature written by Demircioğlu, Ayas \& Demircioğlu (2006) with the title "Narratives and Teaching Chemistry", the objectives of narration which begins to attract intensive attention in chemistry education are clearly defined. To exemplify those objectives, the following is stated: associating chemistry concepts to daily life; establishing social and technological structure in chemistry class properly; helping to improve students' attitude towards and admiration of the class through presentations of scientific concepts in daily situations; and raising individuals with scientific literacy. Hence, this approach allows students to participate in the class actively in order to assist them to make their learning meaningful and to improve their concepts. Teaching materials built referring to this approach contribute to students to take responsibility more than what they learn. Within this context, the literature mentioned above includes and covers the objectives of the teaching program based on narratives, explanatory narratives and information about the usage of chemistry narratives in learning environment. As the literature concerns, chemistry narratives can motivate students to learn, realize the meaningful learning and eliminate misconceptions.

As a result of the researches conducted both in our country and in the world, the literature titled "The Impact of Problem-Based Learning Approach in Terms of Teaching Electrolyze and Battery", authored by Aydoğdu (2012) identifies that the following issues have gained greater importance: thinking skill, problem-solving skill, defining the learning requirements, ability to construct learning by itself, making information functional and conducting teamwork, and this kind of student-centered teaching improves student achievement. In this literature, problem-based learning method, one of the student-centered teaching methods, is discussed. It is stated that in this study, the meaningful learning of Science Students in the Faculty of Education, Hacettepe University, in terms of Electrolyze and Battery subjects is discussed, and their attitude towards chemistry class is examined through the problem-based learning method. Experimental method is used in the literature and it is stated that students have been applied the scientific processing skill test, electrochemistry achievement test and chemistry attitude scale. As stated in the literature analysis, achievements of students in the experimental group, who were applied problem-based learning approach, have been gradually improved in the chemistry class. In this context, it is determined that the level of eliminating misconceptions and realizing meaningful learning for the students in the experimental group is much better compared to the students in the control group.

Chart. Categorizing Researches on Present Chemistry Education

\begin{tabular}{lll}
\hline METHOD & SUBJECT & SAMPLING \\
\hline Conceptual Change Approach & Solubilty Equilibrium & $10^{\text {th }}$ graders \\
Analogy & Chemical Equilibrium & $10^{\text {th }}$ graders \\
Concept Cartoons & Solutions & $4^{\text {th }}$ and $5^{\text {th }}$ graders \\
Active Learning Practices & Ionic Bonds & $9^{\text {th }}$ graders \\
Computer-assisted Learning Method & Electrochemistry & $11^{\text {th }}$ graders \\
Using Models in Teaching & Interactions between Chemical Species & Freshmen \\
Narratives and Chemistry Education & Periodic System & High School Students \\
Problem-Based Learning Approach & Electrolyze and Battery & Students of Science Teaching \\
\hline
\end{tabular}

When the chard above is examined, it is observed that studies on various subjects, particularly on abstract subjects in terms of misconceptions are carried out in the present chemistry education literatures. When these studies are examined, it is ascertained that mainly high school students are involved and studied with. Moreover, it is possible to claim that methods based on the constructivist approach are preferred to eliminate misconceptions.

\section{Results and Suggestions}

This research is conducted with the objective to examine misconceptions identified in literatures, to study what those misconceptions are and how they are eliminated in literatures. As a conclusion of this study, many misconceptions, particularly on dissolution, melting, solubility equilibrium, chemical equilibrium, ionic bond, covalent bond, double and triple bonds, hydrogen bond and its molecular geometry, activity, electrolyze and battery, have been identified in related literatures for each age group of students in chemistry education.

Within the framework of another objective of the study, the methods to eliminate the misconceptions identified in the 
literatures are examined. Considering this, it is concluded that traditional teaching methods do not function when it comes to eliminate misconceptions, instead, methods based on the constructivist approach are preferred. As a result of literature analysis, those methods developed on the basis of the constructivist approach are exemplified as follows: conceptual change approach, analogy, concept cartoons, modeling, computed-assisted teaching, narratives and chemistry education and finally problem-based learning method. Furthermore, teachers should identify the preliminary knowledge related to the particular subject in order to eliminate misconceptions. If this preliminary knowledge includes misconceptions, teaching should be planned in a way to eliminate those misconceptions. Teachers should awaken to the inadequacy of teaching methods solely consisted of information transfer and use different teaching techniques.

\section{References}

Aydoğdu, C. (2012). The Impact of Problem-Based Learning Approach in Terms of Teaching Electrolyze and Battery, Hacettepe University, Faculty of Education, 42, 48-59.

Bilgi, M., \& Şahin, M. (2012). The Impact of using computer-assisted teaching material on student achievement in terms of teaching activity in elements. Türk Fen Eğitimi Dergisi (Turkish Science Education Journal), 9(4), 146-166.

Bilgin, İ., \& Geban, Ö. (2001). Eliminating misconceptions of High school second grade students on chemical equilibrium by the means of Analogy. Hacettepe University, Faculty of Education Journal, 32, 20-26.

Canpolat, N., Pınarbaşı, T., Bayrakçeken, S., \& Geban, Ö. (2004). Some Comman Misconceptions in Chemistry Gazi University, Faculty of Education Journal, 24(1), 135-146.

Coll, R. K., \&Taylor, N. (2001). Alternative conceptions of chemical bonding held by upper secondary and tertiary students. Res. Sci. Technol. Education, 19, 171-191. https://doi.org/10.1080/02635140120057713

Day, A.R. (1998). How to write and publish scientific papers. Memórias do Instituto Oswaldo Cruz, 93(3), 423-424. https://doi.org/10.1590/S0074-02761998000300029

Demircioğlu, H., Ayas, A., \& Demircioğlu, G. (2006). Narratives and Chemistry Education, Hacettepe University, Faculty of Education Journal, 30, 110-119.

Glesne, C. (2012). An Introduction to Qualitative Research. (translated by A. Ersoy ve P. Yalçınoğlu, Ankara: Anı.

Kabapınar, F., (2005). Concept Cartoons as a teaching method to be used in science classes in terms of the contributions to the Constructivist Learning process. Kuram ve Uygulamada Eğitim Bilimleri, 5(1), 101-146.

Kayalı, H., \& Tarhan, L. (2004). A guiding material implementation based on the constructivist-active learning to eliminate misconceptions on ionic bonds. Hacettepe University, Faculty of Education Journal, 27, 145-154.

Kılıç, D. (2007). The impact of the Teaching Analogy model on eliminating misconceptions of grade -9 students in terms of chemical bonds. Postgraduate thesis, Gazi University, Ankara.

Miles, M. B., \& Huberman, A. M. (1994). Qualitative data analysis: An expanded sourcebook, Sage Publications.

Nicoll, G. (2001). A report of undergraduates bonding misconceptions. Int. J. Sci. Educ., 23(7), 707-730. https://doi.org/10.1080/09500690010025012

Novick, S., \& Nussbaum, J. (1981). Pupils' understanding of the particulate nature of matter: A cross-age study. Science Education, 65(2), 187-196. https://doi.org/10.1002/sce.3730650209

Önder, İ., \& Geban, Ö. (2006). The impact of conceptual change texts-based teaching on students' understanding the solubility equilibrium subject. Hacettepe University, Faculty of Education Journal, 30, 166-173.

Özmen, H. (2007). The effectiveness of conceptual change texts in remanding high school students' alternative conceptions concerning chemical equilibrium. Asia Pacific Education Review, 8, 413-425. https://doi.org/10.1007/BF03026470

Peterson, R., Treagust, D. F., \& Garnett, P. (1989). Development and application of a diagnostic instrument to evaluate grade-11 and 12 students concepts of covalent bonding and structure following a course of instruction, J. Res. Sci. Teach, 26, 49-71. https://doi.org/10.1002/tea.3660260404

Raymond, F., Peterson, R., \& Treagust, DF. (1989). Grade - 12 students' misconceptions of covalent bonding and structure. J. Chemical Education, 66(6), 459-460. https://doi.org/10.1021/ed066p459

Şen, Ş., \& Yılmaz, A. (2013). The reasons of misconceptions according to chemistry teacher candidates, Buca Faculty of Education Journal 35, 59-95.

Sesen, B. A., \& İnce, E. (2010). Internet as a source of misconception: Radiation and radioactivity. TOJET: The Turkish 
Online Journal of Educational Technology, 9(4), 94-100.

Skelly, K. M., \& Hall, D. (1993). The development and validation of a categorization of sources of misconceptions in chemistry. Paper presented at the Third International Seminar on Misconceptions and Educational Strategies in science and Mathematics, Ithaca, NY.

Sweller, J. (1988). Cognitive load during problem solving: Effects on learning. Cognitive Science, 12(2), $257-285$. https://doi.org/10.1207/s15516709cog1202_4

Üce, M. (2015). Constructing models in teaching of chemical bonds, Ionic bond, covalent bond, double and triple bonds, hydrogen bond and molecular geometry. Educational Research and Reviews, 10, 491-500. https://doi.org/10.5897/ERR2014.1940

Ünal, S., Özmen, H., Demircioğlu, G., \& Ayas, A. (2002). A study on defining the level of understanding and misconceptions in terms of chemical bonds for high school students $V$. Fen Bilimleri ve Matematik Eğitimi Kongresi, (5 ${ }^{\text {th }}$ Science and Math Education Congress) Ankara, Türkiye. 846-852.

Ürek, R., \& Tarhan, L. (2005). A Practice of active Learning based on constructivism to eliminate misconceptions on covalent bonds. Hacettepe University, Faculty of Education Journal, 28, 168-177.

Veiga, M., Pereira, D., \& Maskill, R. (1989). Teachers' language and pupils' ideas in science lessons: Can teachers avoid reinforcing wrong ideas? International Journal of Science Education, 11(4), 465-479. https://doi.org/10.1080/0950069890110410

Yıldırım, A., \& Şimşek, H. (2008). Qualitative Research Methods in Social Sciences, Ankara: Seçkin.

Y1lmaz, A., \& Morgil, İ. (2001). Identifying the misconceptions of students in terms of chemical bonds Hacettepe University, Faculty of Education Journal, 20, 172-178.

\section{Copyrights}

Copyright for this article is retained by the author(s), with first publication rights granted to the journal.

This is an open-access article distributed under the terms and conditions of the Creative Commons Attribution license which permits unrestricted use, distribution, and reproduction in any medium, provided the original work is properly cited. 